\title{
Finite Element Modelling of Edge Radius Effect in Micro Turning Process
}

\author{
Ahmet HASCELIK \\ Department of Mechanical and Metal \\ Technology, İscehisar Vocational \\ School of Higher Education, \\ Afyon Kocatepe University, \\ Afyonkarahisar, Turkey \\ ahascelik@aku.edu.tr
}

\author{
Kubilay ASLANTAS \\ Department of Mechanical \\ Engineering, Faculty of Technology, \\ Afyon Kocatepe University, \\ Afyonkarahisar, Turkey \\ aslantas@aku.edu.tr
}

\author{
Waleed AHMED \\ Mechanical Engineering Department \\ College of Engineering, \\ UAE University \\ Al Ain, Abu Dhabi, UAE \\ w.ahmed@uaeu.ac.ae
}

\begin{abstract}
Micro-turning is very similar to conventional turning, but is a cutting operation in which the tool geometry effect is more important. For this reason, the cutting geometry and cutting parameters used in micro turning must be carefully selected. In this work, during the machining of the Ti6Al4V alloy in micro cutting conditions, the effect of different edge radii of the insert on the cutting forces, tool stresses, and residual stresses was investigated. The appropriate material model is determined by comparing the force data obtained from the cutting experiments with the model results. Numerical solutions have been made for different edge radii. The cutting speed and depth of cut were considered as constant. Different feed rate values and different edge radii were chosen as variables. According to the results obtained, the increasing edge radius causes an increase in cutting (especially in the direction of feed) forces. Increasing edge radius causes a decrease in tool stresses. Most importantly, the increase of the edge radius causes the residual stresses under the surface to occur, usually in the form of compression.
\end{abstract}

Keywords-Micro Turning; Finite Element Analysis; Edge Radius

\section{INTRODUCTION}

In the manufacturing sector, the miniaturization of the parts over time, the need for smaller parts with reduced dimensions and high precision caused new searches. All these requirements, with the development of technology, have revealed micro manufacturing. Nowadays, micro manufacturing has become one of the popular research topics due to all these requirements. In recent years, many studies have been carried out and continued to solve the problems encountered in the manufacturing of micro parts. [1].

The micro-mechanical machining method makes it possible to produce workpieces at high speed and high precision. The difference of micro-mechanical machining with other methods (thermal and chemical); the higher chip volume is removed at higher speed. Micro-mechanical machining methods include drilling, milling, and turning. In microturning, the depth of cut and the feed value are very close to the workpiece grain size. Therefore, in micro-mechanical machining, the micro-definition is used because both the cutting geometry and the chip cross-section are of a very small size. [2-3]. The workpiece must rotate at high speeds in order to perform the cutting process. This leads to rapid tool wear in micro tools [4]. The wear mechanism, which causes damage to the micro-tools, is usually the abrasive wear mechanism. As a result of abrasive wear, both tool geometry, and edge radius change. This results in increased cutting forces and the deterioration of surface quality in the micro-cutting process [5-6].

Micro-turning is an effective way to produce micro cylindrical or axial symmetrical parts. In fact, turning microparts is not a new method. However, the size of the parts becomes very small and some problems arise. Some of those; a) the reduction of the diameter of the workpiece increases the risk of bending, b) with the effect of bending, the removed chip section changes; c) very small depth of cut and feed rate, causes ploughing. Particularly, in cutting operations under critical feed and chip depth of cut, residual stresses occur under the machined surface. These are often residual stresses in the form of compression [7], but sometimes in the form of a tension [8]. Naturally, these residual stresses affect the next cutting process (in particular, cutting force and surface quality). The compressive residual stresses occurring under the surface cause the fatigue life of the part to increase. Tension residual stresses cause fatigue life of the part to decrease. As much as the size of these stresses, it is also important how much depth is effective from the surface. In the determination of these stresses, although experimental approaches are used, it is an expensive and time-consuming method. Therefore, numerical methods are the most widely used technique for obtaining the change of residual stresses under the surface after machining.

The aim of this study was to investigate the changes in the sub-surface stresses of Ti6Al4V alloy, which is frequently used in dental implants, under micro cutting conditions. First of all, the validity of the material model used was demonstrated by experimental results. Experimentally obtained cutting forces and chip geometry were compared with the modeling results. Considering the different edge radii, 
finite element solutions were carried out. Both radial and circumferential residual stresses occurring on the machined surface were obtained. In addition, the change of stresses on the tool surface and the effect of edge radius on the chip form were also determined.

\section{MATERIAL AND METHOD}

\section{A. Experimental Setup}

In the study, an experimental setup was used in which all micro-mechanical cutting operations (drilling, milling, and turning) can be performed. The experimental setup is similar to a horizontal machining center, the workpiece is fixed to the spindle. The spindle used is IMT brand and can reach up to $60000 \mathrm{rpm}$. Linear slides (Thorlabs) supported by microstepper motors are used for axis movements. The maximum travel distance of the slides is $150 \mathrm{~mm}$ and the sensitivity is $0,1 \mu \mathrm{m}$. The spindle is mounted on the guideway which provides $\mathrm{X}$-axis movement. The cutting tool is fixed on the mini dynamometer and the dynamometer is fixed on the $\mathrm{Y}$ guideway. The depth of cut is provided by the Y-axis. The tool holder is specially designed for an approach angle of $90^{\circ}$ and can be fixed to the dynamometer. In the experiments, a USB microscope with a magnification of 50-800 was used in order to be able to observe the cutting zone more clearly. The entire system is mounted on a non-vibrating optical table [5]
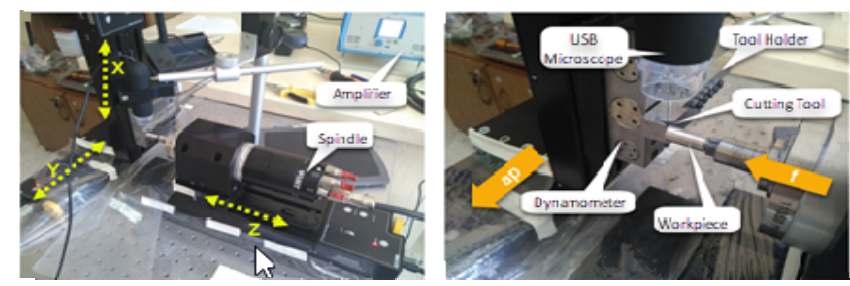

Figure 1: General view of the system used in micro turning experiments.

\section{B. Cutting Tool and Cutting Parameters}

The cutting tool is supplied from Kennametal and coated with TiAlN (coating thickness $2 \mu \mathrm{m}$ ). The ISO code for the tool is TDHB07T1202 and no standard tool holder is used. The nose radius of the cutting tool is approximately $\mathrm{R}_{\varepsilon}=20$ $\mu \mathrm{m}$ and the edge radius ( $\mathrm{Re}$ ) is approximately $7.25 \mu \mathrm{m}$. The rake angle of the cutting tool is zero and the clearance angle is $15^{\circ}$. In the study, depth of cut, ap $=40 \mu \mathrm{m}$ and cutting speed $\mathrm{Vc}=100 \mathrm{~m} / \mathrm{min}$ were considered. In the study, three different feed rates ( $\mathrm{f}=10 \mu \mathrm{m}, 20 \mu \mathrm{m}, 40 \mu \mathrm{m})$ value were used. The experiments were carried out under dry cutting conditions, and as a result, the cutting forces, tool stresses and the change of sub-surface stresses.

\section{Finite Element Analysis and Material Model}

Deform 2D software was used for finite element analysis. The minimum element size used in the finite element model of the workpiece is smaller than one-fourth of the feed value. The cutting speed is given to the workpiece and modeled as elasto- plastic. In the chip formation process, a finite element mesh was formed for each solution interval using the re-meshing technique. At each step, the resulting cutting forces and cutting temperature were recorded. The finite element model used in the solutions is given in Figure 2. In the modeling, 4111 and 1154 quadratic elements were used for workpiece and cutting tool geometry respectively. The problem was modeled under plane strain conditions.

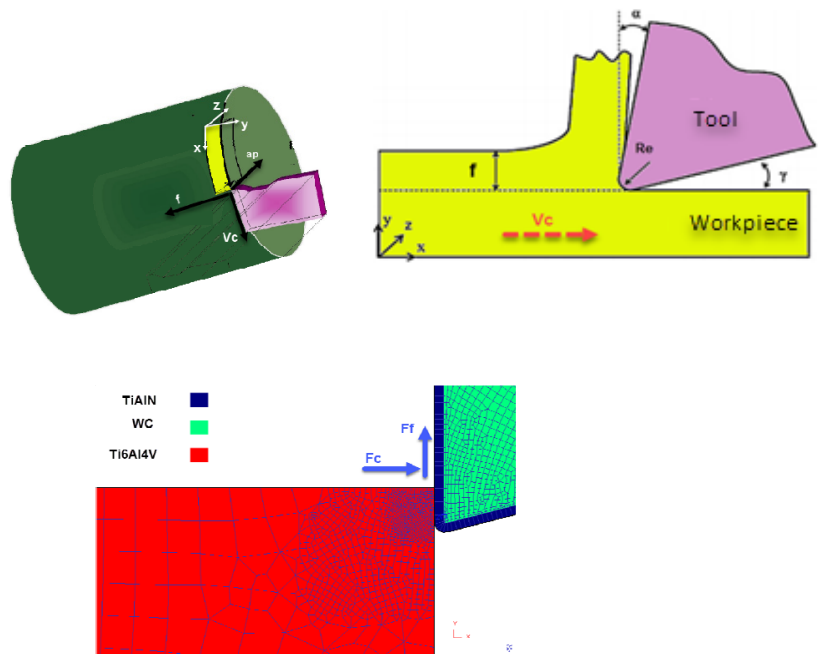

Figure 2: Two-dimensional expression of the turning process and the workpiece and cutting tip mesh structure.

The material model is very important in modeling the machining process. To obtain accurate results, a model should be used that takes into account the behavior of the material at high temperature and high deformation rates. The JohnsonCook (J-C) material model is the most commonly used material model for the modeling of machining. The modified Johnson-Cook material model was also used in this study [8]. The general expression of the model is given in Equation 1. The final multiplier of this model takes into account the thermal softening that occurs due to the temperature.

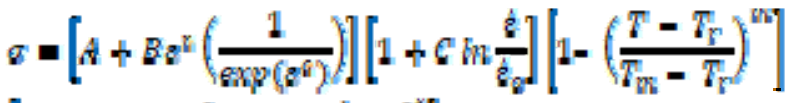

$$
\begin{aligned}
& {\left[D-(1-D)\left[\tanh \frac{1}{(a+\beta)^{r}}\right]\right]} \\
& D=1-\left(\frac{7}{w_{n}}\right)^{n} p=\left(\frac{8}{q_{m}}\right)^{2}
\end{aligned}
$$

The material yield stress constant $\mathrm{A}=1343 \mathrm{MPa}$ given in Equation 1, the hardening modulus of the material $\mathrm{B}=$ $1092 \mathrm{MPa}$, the hardening coefficient $\mathrm{n}=0.22$, the strain rate $\mathrm{C}$ $=0.06$, the thermal softening coefficient of the material is $\mathrm{m}=$ 1.82 [8]. Other parameters used in Equation 1, a $=2, \mathrm{~b}=1, \mathrm{~S}$ $=5$ and $\mathrm{d}=0.5$ was used for Ti6A14V alloy [8]. These values are taken from the literature for Ti6Al4V alloy and are 
generally determined by various iteration methods or trial and error methods [12].

Ti6Al4V alloy, which is used in this study, was subjected to the annealing process after production and no aging was applied. In the SEM analysis, the mean grain size was determined to be $11.7 \mu \mathrm{m}$ [13]. The shear friction factor of the tool-chip interface was fixed and taken as 0.6. The heat transfer coefficient of the workpiece was taken as $100 \mathrm{~kW} / \mathrm{m}^{2}$. After the elasto-plastic solution, the cutting tool was removed from the model and a second solution was carried out until the temperature of the entire workpiece was reduced to $20^{\circ} \mathrm{C}$. Therefore, both radial and peripheral residual stresses on the machined surface have been obtained. For the stresses on the tool surface, a second solution was carried out by removing the workpiece from the model.

\section{RESUltS AND DiscusSION}

\section{A. Variation of Cutting Forces}

In the experimental part of the study, cutting tests were performed at three different feed rates for the edge radius $\mathrm{Re}=$ $7.25 \mu \mathrm{m}$ of the cutting tool. The obtained cutting force data was compared with the values obtained after modeling and the material model was verified. Figure 3 shows the comparison of the cutting forces obtained at different feed values for $\mathrm{Vc}=$ $100 \mathrm{~m} / \mathrm{min}$. As can be seen from Figure 3-a, experimental cutting force data and modeling results are very close to each other and the amount of error is acceptable. Another remarkable point in Figure 3-a is that the $\mathrm{Ff} / \mathrm{Fc}$ ratio approaches 1, depending on the decreasing feed value. If this ratio is close to 1 , it means that the cutting process takes place by means of the ploughing mechanism rather than the shear mechanism. In order to verify this expression, the numerical solution results for different edge radii are given in Figure 3-b. As can be seen from Figure 3-b, the Fc force is greater than the $\mathrm{Ff}$ force on the edge radius $(\mathrm{Re}=2,25 \mu \mathrm{m})$ smaller than the feed value. When the edge radius is equal to the feed value, the $\mathrm{Fc}$ force and the $\mathrm{Ff}$ force are close to each other. When using an edge radius greater than the feed value, the force Ff appears to be much larger than the Fc force. If the edge radius is too large, it causes the tool to behave like a cutter with a negative rake angle. This makes chip formation difficult and increases the feed force. In Figure $3-a$, it is possible to say that the feed force does not increase significantly. This may be due to the fact that the friction coefficient does not change much at the tool-chip interface. However, due to the increase of the edge radius, the tool-chip contact length increases. Increased tool-to-chip contact length also causes friction to increase. As a result, the feed force increases. (Figure 3-b).

\section{B. Tool Stresses}

Depending on the edge radius, the variation of the equivalent stresses on the cutting tool surface is given in
Figure 4. The results given in Figure 4 were obtained for $\mathrm{Vc}=$ $100 \mathrm{~m} / \mathrm{min}$ and $\mathrm{f}=10 \mu \mathrm{m}$. As seen from Figure 4 , the equivalent stresses tend to decrease at the point where the coating material ends. Although the increase of the edge radius from 2.25 to $7.25 \mu \mathrm{m}$ causes some stresses to increase, the stress values obtained for $\mathrm{Re}=15 \mu \mathrm{m}$ are smaller. The increased edge radius will increase the rigidity of the tool tip. As a result, the stresses on the tool tip are expected to decrease. However, increased edge radius results in increased cutting forces. Therefore, the stress value obtained for $\mathrm{Re}=$ $7.25 \mu \mathrm{m}$ was higher than $\mathrm{R}=2.25 \mu \mathrm{m}$. In other words, the cutting forces acting on the tool are more dominant than the increase in the rigidity of the increasing edge radius.
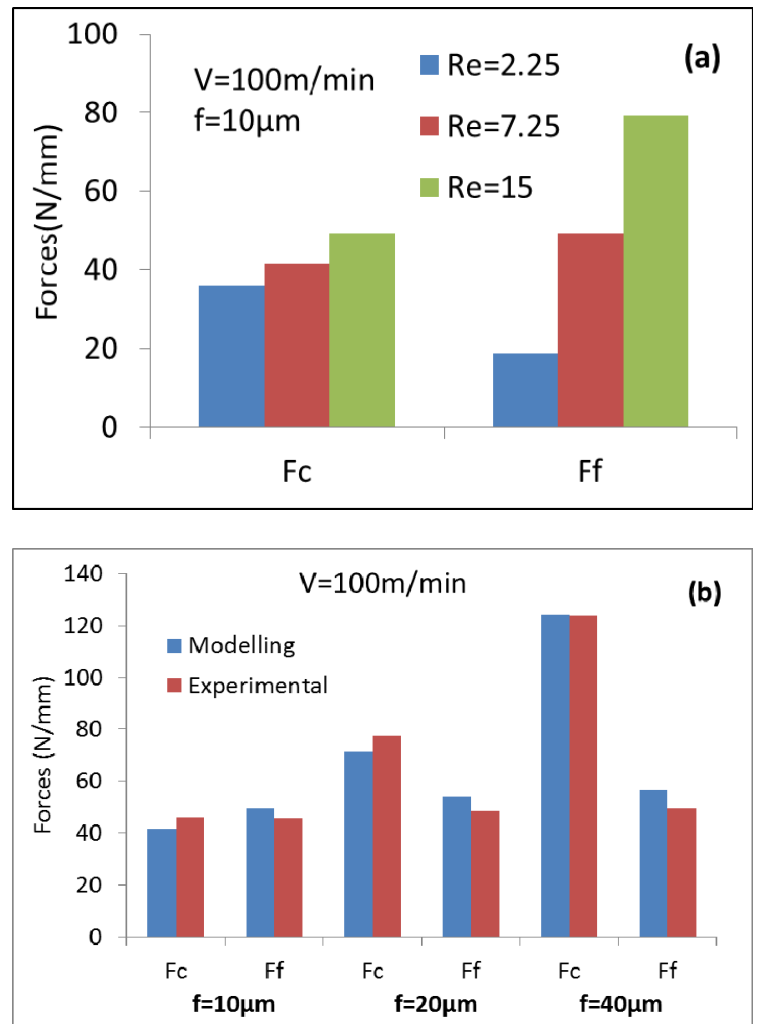

Figure 3: Effect of feed rate (f) and edge radius (Re) on cutting forces.

\section{Effect of Edge Radius and Feed Rate on Chip Form}

Particularly in the micro-cutting process, the edge radius directly affects the chip formation mechanism. The increased edge radius makes it difficult for the cutting tool to plunge into the workpiece. Therefore, the cutting forces increase. Besides, the shape of the chip changes. In Figure 5, the effect of different edge radii on the chip form is given with constant feed rate $(\mathrm{f}=10 \mu \mathrm{m})$ and constant cutting speed $(\mathrm{V}=100 \mathrm{~m} /$ min). In Figure 5, the saw-tooth chip type is represented by the maximum height, h2, minimum height, $h 1$, and step, L1. L1 value increases with increasing edge radius. In a sense, segmentation of the saw-tooth chip (the number of teeth per unit of time) is reduced. This is seen in the chip form in Figure 
5. Increased segmentation means that the time interval between the minimum and maximum values of the cutting force increases. The increased edge radius caused a change in the shear angle by creating a negative rake angle effect. The increased radius resulted in a decrease in h1, while the value $\mathrm{h} 2$ remained almost constant.
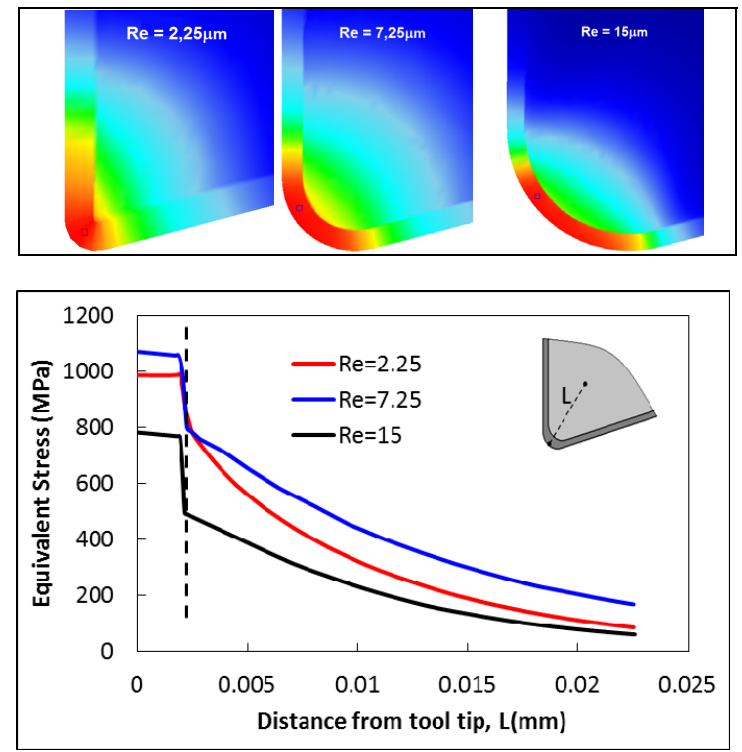

Figure 4: Variation of tool stresses according to different edge radius.

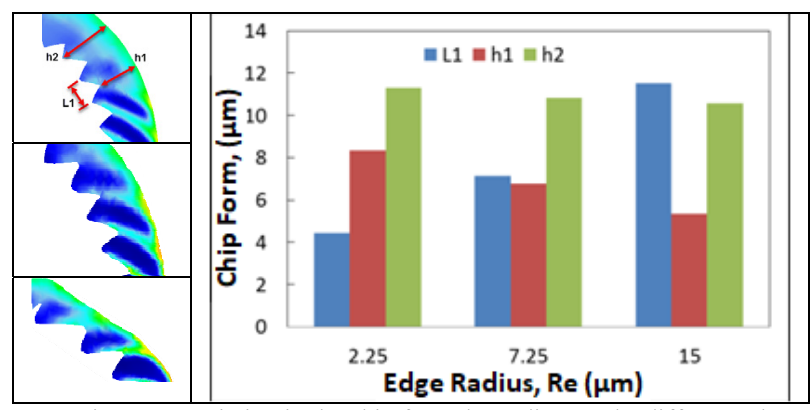

Figure 5: Variation in the chip form depending on the different edge radius.

Figure 6 shows the comparison of the chip geometry obtained for different feed values. In Figure 6-a, the change of the maximum chip height $\left(\mathrm{h}_{2}\right)$ and the change in the distance $\left(\mathrm{L}_{1}\right)$ between the chip-segments are given in Figure 6-b. Due to the fact that the chip section was very small, SEM analysis of the chip was performed after the cutting process. Caliper software is used for measurements. As can be seen from Figure 6, the experimental values are higher than the values obtained from the modeling. With increasing feed rate, both $\mathrm{L}_{1}$ and $h_{2}$ increase. Increasing the feed value causes the chip section to increase. As a result, the maximum height of the chip form is also increased. However, the $L_{1}$ value does not show an increase in $h_{2}$ value. As shown in Figure 6-a, the increase in feed rate causes the deformed chip thickness to increase linearly. Increased chip thickness results in increased thickness of chip deformed in the slip region (first deformation zone). Thus, the segmentation of the chip in the first deformation zone becomes difficult. The difference between experimental and modeling is increased due to the insufficiency of the friction model in the tool-chip interface. If different friction models are used at the tool-chip interface, results closer to the experimental can be obtained.
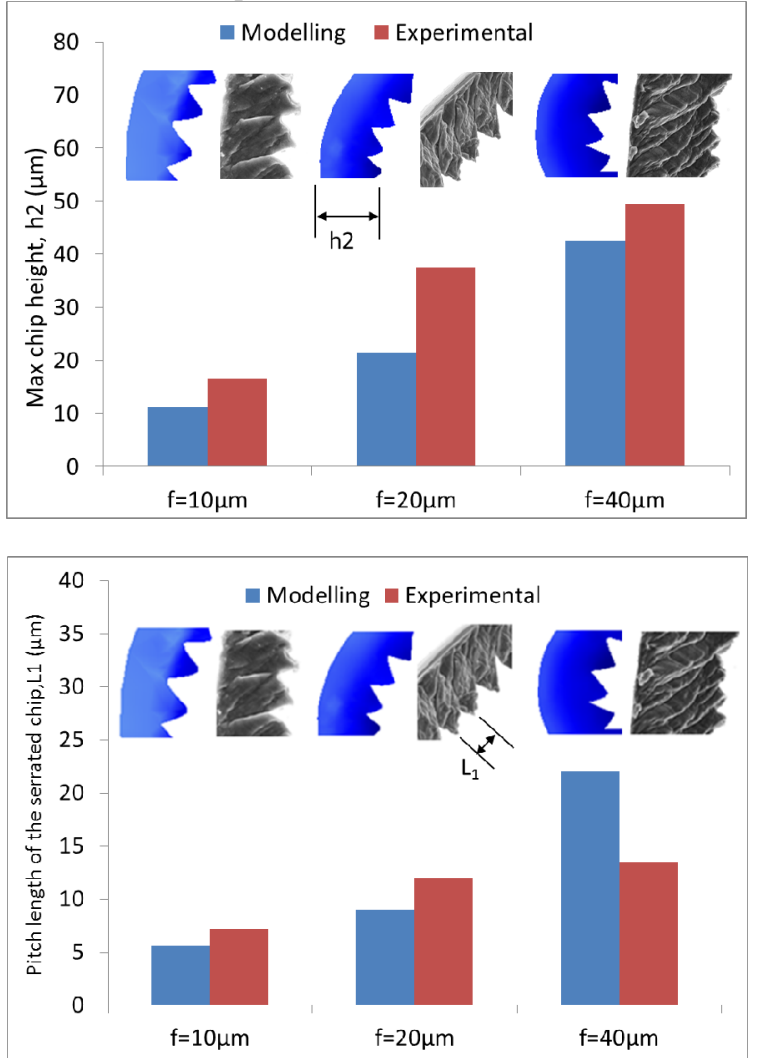

Figure 6. Comparison of the chip form depending on the different feed rates.

\section{Subsurface residual stresses}

After machining, tensile stresses under the surface are undesirable in terms of fatigue life. Therefore, both the direction (compression or tension) and the amount of the residual stresses under the surface should be taken into consideration after machining. However, the determination of residual stresses is not very easy, but it is quite expensive. In Section A, the material model used was validated.

In this section, numerical solutions were made for residual stresses. However, the experimental validation of the residual stresses could not be carried out. Figure 7 shows the change of circumferential and radial residual stresses depending on the depth from the machined surface for $\mathrm{f}=10 \mu \mathrm{m}$ and $\mathrm{Vc}=$ $100 \mathrm{~m} / \mathrm{min}$. As can be seen from Figure 7, the circumferential and radial residual stresses occurring in the machined surface are in the form of compression. These results are similar to the studies in the literature [9-11]. However, depending on the radius of the edge, the direction of compression stresses 
becomes tensile stress. For $\mathrm{Re}=2.25 \mu \mathrm{m}$, stresses occurring in both the circumferential and radial directions occur at a depth of $10 \mu \mathrm{m}$. With increasing edge radius, the circumferential residual stresses are slightly reduced while the radial direction increases slightly. In both cases, the compressive stresses are effective at a depth of $20 \mu \mathrm{m}$. The increased edge radius causes both residual stresses in both the circumferential and radial directions. Especially for $\mathrm{Re}=15 \mu \mathrm{m}$, after $20 \mu \mathrm{m}$ depth, residual stresses are formed in the tension direction. However, tensile stresses after $20 \mu \mathrm{m}$ for $\mathrm{Re}=7.25 \mu \mathrm{m}$ are at lower levels.
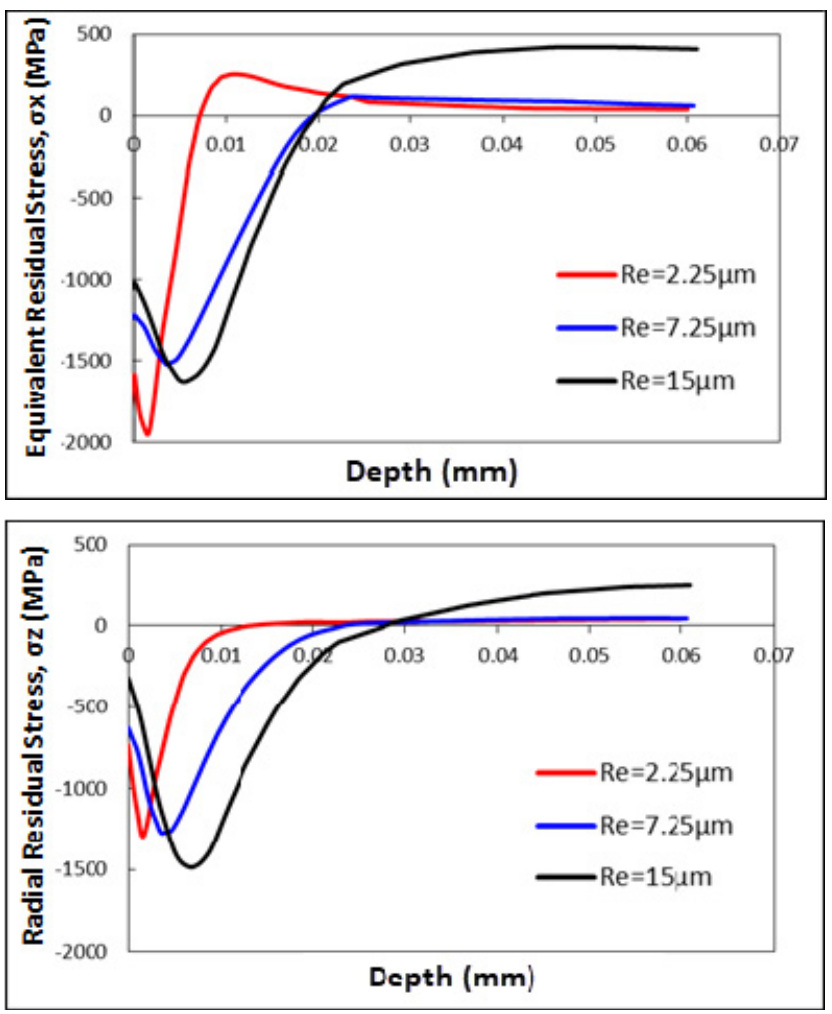

Figure 7: Variation of residual stresses under surface according to different edge radius.

\section{CONCLUSIONS}

In this study, the effect of feed rate and tool edge radius on cutting forces, chip form, tool stresses, and subsurface residual stresses were investigated in micro turning. Residual stresses and tool stresses were obtained by the finite element method. The accuracy of the material model used in modeling was determined based on the cutting forces. It is possible to list the results obtained after the study as follows:

- In micro turning, the increase in edge radius causes $\mathrm{Ff} / \mathrm{Fc}$ to grow. The growth of this ratio is an indication of the fact that the cutting process is realized by the mechanism of ploughing rather than the shear mechanism.

- Increased edge radius increases tool tip stiffness. Thus, the tool stresses are reduced.

- In micro-turning of the Ti6Al4V alloy, residual stresses under the surface are predominantly compression. However, the increased edge radius causes these stresses to return to the tension at a certain depth.

- The increased edge radius can affect the fatigue life of the machined geometry positively. However, it should be kept in mind that the increased edge radius will adversely affect the surface roughness.

\section{REFERENCES}

[1] Aslantaş K., Şahan Ö., 2017 "Ti6Al4V alaşımının mikro ișleme şartlarında yüksek hızda tornalanması", 8.Uluslararas Talaşıı İmalat Sempozyumu, s.101-110, Antalya.

[2] Dornfeld, D., Min, S., Takeuchi, Y., 2006, "Recent Advances in Mechanical Micromachining" Annals of the CIRP, Cilt: 55(2), s.745-768

[3] Alting, L., Kimura, F., Hansen, H.N., Bissacco, G., 2003, "Micro Engineering" Annals of CIRP, Cilt 52(2), s.635-657.

[4] Ucun I., Aslantas K., Bedir F., 2013, “ An experimental investigation of the effect of coating material on tool wear in micro milling of Inconel 718 super alloy", Wear. 300, 8-19.

[5] Thepsonthi T., Özel T., 2012, "Multi-objective process optimization for micro-end milling of Ti-6Al-4V titanium alloy", Int J Adv Manuf Tech 63, 903-914. 32.

[6] Bajpai V., Kushwaha AK., Singh RK., 2013, "Burr Formation and Surface Quality in High Speed Micromilling of Titanium Alloy (Ti6Al4V)". Micro and Nano Technol; Sustainable Manuf 2 10-14.

[7] Niesłony P., Grzesik W., Laskowski P., Sienawski J., 2014, "Numerical and Experimental Analysis of Residual Stresses Generated in the Machining of Ti6Al4V Titanium Alloy", Procedia CIRP. 13, 78-83.

[8] Özel T., Ulutan D., 2012, "Prediction of machining induced residual stresses in turning of titanium and nickel based alloys with experiments and finite element simulations", CIRP Annals Manufacturing Technology. 61, 547-550.

[9] Abboud E., Shi B., Attia H., Thomson V., Mebrahtu Y., 2013, "Finite element-based modeling of machining-induced residual stresses in Ti-6Al-4V under finish turning conditions", in: Procedia CIRP, pp. 63-68.

[10] Afazov S., Ratchev S., Becker A., Liu S., Segal J., Numerical analyses of turning-induced and mapped Ti6A14V residual stresses for a disc subjected to centrifugal loading, International Journal of Automation Technology. 5 (2011) 326-333.

[11] Ratchev S.M., Afazov S.M., Becker A.A., Liu S., 2011, "Mathematical modelling and integration of micro-scale residual stresses into axisymmetric FE models of Ti6A14V alloy in turning, CIRP Journal of Manufacturing Science and Technology". 4, 80-89.

[12] Ducobu F., Riviere-Lorphevre E., Filippi E., 2017 “On the importance of the choice of the parameters of the Johnson-Cook constituve model and their influence on the results of a Ti6Al4V orthogonal cutting model" International Journal of Mechanical Sciences, Volume 122, Page 143-155

[13] Yang D., Zhanqiang L., 2016, "Quantification of Microstructural Features and Prediction of Mechanical Properties of a Dual-Phase Ti6A14V Alloy" Materials, 9, 628 